\title{
The TDR MOOC training in implementation research: evaluation of feasibility and lessons learned in Rwanda
}

Cole Hooley ${ }^{1 \dagger}$, Ana A. Baumann ${ }^{1 \dagger}$, Vincent Mutabazi ${ }^{2} \mathbb{D}$, Angela Brown ${ }^{3}$, Dominic Reeds ${ }^{4}$, W. Todd Cade ${ }^{5}$, Lisa de las Fuentes ${ }^{3}$, Enola K. Proctor ${ }^{1}$, Stephen Karengera ${ }^{2}$, Kenneth Schecthman ${ }^{6}$, Charles Goss ${ }^{6}$, Pascal Launois ${ }^{7}$, Victor G. Davila-Roman ${ }^{3}$ and Eugene Mutimura ${ }^{2 *}$

\begin{abstract}
Background: Hypertension (HTN) affects nearly 1 billion people globally and is a major cause of morbidity and mortality. In low- and middle-income countries (LMICS), HTN represents an unmet health care gap that can be addressed by strengthening national health care systems. The National Heart, Lung, and Blood Institute recently funded the T4 Translation Research Capacity Building Initiative in Low Income Countries (TREIN) program to build capacity in dissemination and implementation (D\&l) research in HTN in LMICs. The Special Programme for Research and Training in Tropical Diseases (TDR) at the World Health Organization (WHO) recently developed a massive open online course (MOOC) to train in D\&l. Herein, we report on the use of the TDR WHO MOOC in D\&l for the TREIN program in Rwanda, assessing feasibility of the MOOC and D\&l competencies after MOOC training.

Methods: Participants in one-group MOOC training completed pre- and post-training questionnaires to assess dissemination and implementation (D\&l) competency outcomes and feasibility. D\&I competencies were measured by use of a scale developed for a US-based training program, with the change in competency scores assessed by paired $t$ test. Feasibility was measured by completion of homework and final project assignment and analyzed using descriptive statistics.

Results: Of the 92 trainees enrolled, 35 (38\%) completed all MOOC components. D\&l competency scores showed strong evidence of improvements from pre- to post-test. The full-scale average score improved by an average of 1.09 points, representing an effect size of 1.25 (Cl 0.48-2.00); all four subscales also showed strong evidence of improvements. Trainees reported challenges to $\mathrm{MOOC}$ course completion that included technological issues (i.e., limited internet access) and competing demands (i.e., work, family).

(Continued on next page)
\end{abstract}

\footnotetext{
*Correspondence: mutabazivincent@gmail.com;

eugene.mutimura@gmail.com

${ }^{+}$Cole Hooley and Ana A. Baumann contributed equally to this work.

${ }^{2}$ Regional Alliance for Sustainable Development (RASD) Rwanda, Kigali, Rwanda

Full list of author information is available at the end of the article
}

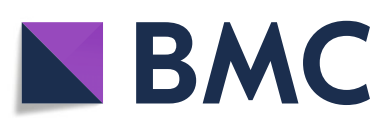

(c) The Author(s). 2020 Open Access This article is licensed under a Creative Commons Attribution 4.0 International License, which permits use, sharing, adaptation, distribution and reproduction in any medium or format, as long as you give appropriate credit to the original author(s) and the source, provide a link to the Creative Commons licence, and indicate if changes were made. The images or other third party material in this article are included in the article's Creative Commons licence, unless indicated otherwise in a credit line to the material. If material is not included in the article's Creative Commons licence and your intended use is not permitted by statutory regulation or exceeds the permitted use, you will need to obtain permission directly from the copyright holder. To view a copy of this licence, visit http://creativecommons.org/licenses/by/4.0/. The Creative Commons Public Domain Dedication waiver (http://creativecommons.org/publicdomain/zero/1.0/) applies to the data made available in this article, unless otherwise stated in a credit line to the data. 
(Continued from previous page)

Conclusions: In the context of LMIC training, the MOOC course was feasible and course completion showed improvement in D\&l competency scores. While the program was designed with a focus on training for tropical diseases, there is potential for scalability to a wider audience of health care researchers, workers, administrators, and policymakers in LMIC interested in D\&l research in non-communicable diseases.

Keywords: Training, D\&l competencies, Low-middle-income countries, Hypertension

\section{Background}

Non-communicable diseases in general and hypertension in particular are the major causes of disability and death worldwide. The World Health Organization (WHO) estimates that deaths caused by cardiovascular diseases, of which hypertension is the major contributor, are threefold higher in low- and middle-income countries (LMICs) vs. high-income countries [1-3]. The development of robust health systems is imperative to tackle the challenges associated with the epidemic of NCDs and HTN. The National Heart, Lung and Blood Institute (NHLBI) recently funded the T4 Translation Research Capacity Building Initiative in Low Income Countries (TREIN) program to build capacity in dissemination and implementation (D\&I) research in non-communicable diseases and particularly in hypertension in LMICs. The Special Programme for Research and Training in Tropical Diseases (TDR) at the World Health Organization (WHO) recently developed a massive open online course (MOOC) to train in D\&I research. Our team in Rwanda and at Washington University in St. Louis partnered with the TDR at the WHO to use their Massive Open Online Course (MOOC) on D\&I research.

As part of its 2018-2030 Strategic Planning [4], the Special Programme for Research and Training in Tropical Diseases aims to strengthen capacity building with the goal of overcoming barriers to the implementation of health interventions. With the hypothesis that local LMIC-driven research can have high-impact, the D\&I research toolkit [5] and free online introductory MOOC were developed. While the MOOC focuses on infectious diseases, many implementation science concepts are cross-disciplinary and can be easily adapted to noncommunicable diseases and hypertension control. Additional benefits to our stakeholders included participation in a structured mentoring program in which peers work together to solve problems, an important component for capacity building [6].

The partnership between Washington University in St. Louis, RASD Rwanda, the Rwandan Ministry of Health, the University of Rwanda, major teaching hospitals and stakeholders, and the Special Programme for Research and Training in Tropical Diseases at WHO was formed to support capacity building in D\&I research. Our team followed Potter and Brough's [7] model of elements for systemic capacity building, which identifies a pyramid of nine separate but interdependent components in a fourtier hierarchy of capacity building needs: (1) structures, systems, and roles; (2) staff and facilities; (3) skills; and (4) tools [7]. Accordingly, the partnership has sought to build skills and equip stakeholders with tools. In 2018, the team implemented a week-long training on the topics of hypertension and cardiovascular diseases, dissemination and implementation science, biostatistics, and research career development. The team also visited and met with stakeholders at the University of Rwanda, major teaching hospitals, and community healthcare facilities to foster clear bi-directional partnerships [8]. The current report builds on our 2018 capacity-building work after the summer in-person meeting. The goals of this paper are to describe the 2019 MOOC-D\&I training, to share preliminary feasibility and dissemination and implementation competency outcomes of the training and to offer lessons learned that can be used to enhance future D\&I training in LMICs. Feasibility was operationalized by completion of the MOOC assignments.

\section{Methods \\ WHO D\&I MOOC program}

The MOOC is a step-by-step online video training (with subtitles in English, French, and Spanish) that covers five modules over six weeks, including (1) identify the challenges of various health settings, (2) assess the appropriateness of existing disease control strategies, (3) develop new interventions and strategies by working with communities and stakeholders, (4) specify implementation research questions, and (5) design rigorous research projects, including identifying implementation research outcomes, evaluating effectiveness, and making plans to scale-up implementation in real-life settings. The MOOC comprises of four milestones that lead to a certificate, as follows: (1) complete homework after each session, (2) satisfactorily pass four quizzes (one for each of the first four first modules), and (3) complete a capstone project at the end of the fifth module. Mentors affiliated with the MOOC program grade the homework; the capstone project is graded by both mentors and MOOC peer trainees, and the quizzes are graded by the computer software. 


\section{Trainees}

As the MOOC is open by invitation only, in collaboration with the MOOC representative (Dr. Pascal Launois), RASD-Rwanda (local NGO) invited potential trainees to apply. MOOC trainees included healthcare workers, researchers, and faculty. Trainees were employed by the Rwandan Ministry of Health, the University of Rwanda College of Medicine and Health Sciences, district hospitals, or other health care facilities. Eligibility criteria included public health researchers and decision-makers, disease control program managers, academics, or others involved in hypertension control programs. No technical or scientific background in implementation science was needed for enrollment, although having a background in health sciences was advantageous. Of the 132 subjects invited to apply, 92 enrolled in the MOOC training.

The unit of analysis was individual trainees in the Special Programme for Research and Training in Tropical Diseases D\&I research MOOC. All individual trainees were assigned to the training condition. Given that this study represents an initial pilot study and was intended to explore feasibility of the training, a sample size was not pre-determined but rather the goal was to enroll as many trainees as possible. There was no blinding in the study. The MOOC ran during October 13 through December 14, 2018. Each learning module lasted one week, but the modules remained open until the closure of the MOOC to allow delayed completion.

\section{Design and outcomes}

This study had two outcomes: training feasibility and competency in D\&I research. MOOC completion using the training's milestone data was used to assess MOOC feasibility [9]. MOOC certificate milestones, which included the four quizzes, and the capstone project, were monitored for each trainee. To assess the competency outcome of the MOOC, a one-group, pre-post study design was used. All Rwandan MOOC trainees were invited to complete a D\&I competencies scale [10-12] at the beginning of the MOOC training and again at the end. The competencies instrument was developed for other US-based D\&I trainings [10, 12]. The instrument includes 43 competencies divided into four subscales: D\&I research skills, theories and research approaches, study designs and analysis, and practice-based considerations $[10,12]$. MOOC enrollees rated themselves on each competency using a 5-point Likert scale (1, not at all, to 5, extremely). The survey was completed via Qualtrics, an online survey platform.

To enhance our understanding of the experiences of participants with the training, after the MOOC course was completed, a member of the research team emailed all MOOC participants soliciting feedback regarding barriers to training, addressing MOOC course and internet connectivity and/or other issues. Qualitative responses from 20 participants were received; all respondents had completed at least one module and the respective quiz. The email responses from MOOC trainees were compiled and reported without further qualitative analysis.

\section{Statistical analysis}

Univariate statistics were conducted to analyze the training feasibility outcome (i.e., homework completion), and a paired $t$ test to assess change in D\&I competencies between pre- and post-test. Trainee average D\&I competency subscale scores and total score from their pre- and post-assessments were calculated [12]. A sensitivity analysis with $t$ tests was conducted using the sample of trainees with partial responses, with full responses, and with full responses removing any outliers. Each model showed strong evidence of improvement from pre- to post-test, with the magnitude of pre-to-post differences decreasing as the sample became more conservative. The findings for the most conservative sample which included trainees with a complete pre- and post-D\&I competency scale and the removal of one outlier are reported $(n=16)$. All data management and analysis was done in Stata v.14.2.

\section{Results}

\section{MOOC participation}

Of the 132 potential trainees invited to participate in the MOOC program, 92 enrolled, 62 completed the first quiz, 58 completed the second and third, 57 completed the fourth, 42 took the final exam, and 35 (38\% MOOC completion rate) completed all requirements to receive the training certificate (Fig. 1). Training completion was the primary outcome to measure training feasibility. The largest attrition occurred between enrollment and first quiz, as $33 \%$ of those who enrolled did not take the first quiz. The second largest point of attrition was between quiz 4 and the final test (26\% attrition).

\section{D\&l competency}

Prior to starting the MOOC training, a pre-training survey was sent to all potential trainees, $n=132$ (3 email addresses bounced, $n=129)$; 74 trainees responded to the pre-training survey and 43 trainees completed the post-training survey. Of the 43 trainees, 17 had complete pre- and post- D\&I competency scales. One outlier was removed from the sample of trainees, reducing the sample to $n=16$.

Table 1 shows demographic characteristics for those who completed both pre- and post-competency surveys $(n=43)$. The majority of the trainees were male (65\%), the average age of trainees was 35 years old (range 25-61), and average years of experience was 4.32 (range 0-15). Over half had a master's degrees (56\%), most worked for the University of 


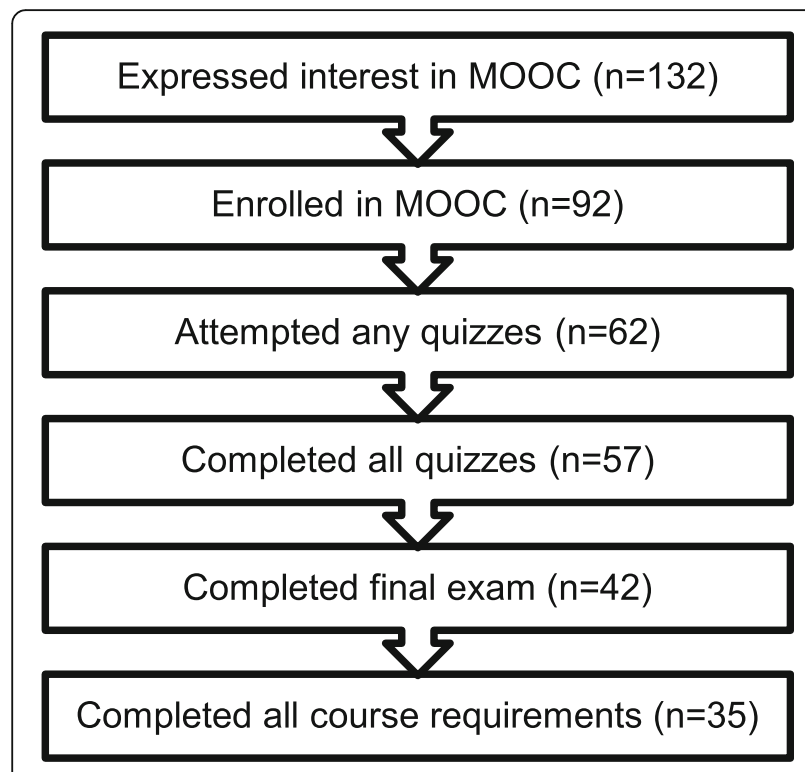

Fig. $1 \mathrm{MOOC}$ training participation attrition

Rwanda (53\%), most had not participated in an earlier D\&I training held during the summer of 2018 (63\%), and most did not have or were unsure if they had a D\&I mentor (52\%). Approximately one third of trainees described their position as assistant lecturer (30\%).

Competency scores showed strong evidence of improvement (pre-test vs. post-test D\&I scores, $n=16$ for all, Table 2) as follows: the average full-scale score improved by 1.09 points (pre-test $2.91 \pm 1.00$ to post-test $4.00 \pm$ $0.70, t(15)=5.16)$, a change that corresponds to an effect size of 1.25 (CI 0.48-2.00). The "definitions, background, and rationale" subscale improved by 1.11 points (pre-test $3.11 \pm 1.05$ to post-test $4.22 \pm 0.47, t(15)=4.6817)$, corresponding to an effect size of 1.35 (CI $0.57-2.11)$. The "theory and approaches" subscale improved by 1.00 points (pre-test $2.99 \pm 1.04$ to post-test $3.99 \pm 0.74, t(15)=$ 4.4173), corresponding to an effect size of 1.11 (CI 0.351.85). The "design and analysis subscale" scores improved by 1.05 points (pre-test $2.79 \pm 1.05$ to post-test $3.84 \pm$ $0.79, t(15)=4.57$ ), corresponding to an effect size of 1.13 (CI 0.38-1.87). The final subscale, "practice-based considerations", improved by 1.18 points (pre-test $2.83 \pm 1.01$ to post-test $4.01 \pm 0.84, t(15)=5.16)$, corresponding to an effect size of 1.26 (CI 0.49-2.02).

Sensitivity analyses were conducted with different samples to ensure the robustness of our conclusions. The results for the pre/post $t$ test sample included the one outlier with complete pre/post responses, in addition to the previously reported analytic sample, are as follows ( $n=17$ for all). The D\&I competency scores improved from pre- to post-test: the average full-scale score improved by 1.23 points (pre-test $2.81 \pm 1.07$ to post-test $4.04 \pm 0.69, t(16)=4.9909)$. The "definitions,
Table 1 MOOC trainee demographics from Rwanda, overall ( $n$ =43), and for those who completed the pre- and postcompetency scores $(n=16)$

\begin{tabular}{lll}
\hline & $N=43$ & $N=16$ \\
\hline Gender, $\boldsymbol{n}$ (\%) & & \\
Male & $28(65 \%)$ & $12(75 \%)$ \\
Female & $14(33 \%)$ & $4(25 \%)$ \\
Missing & $1(2 \%)$ & $0 \%$
\end{tabular}

\begin{tabular}{|c|c|c|}
\hline \multicolumn{3}{|l|}{ Age ( $m \pm s d$, range) } \\
\hline Trainee age & $35 \pm 7(25-61)$ & $35 \pm 6.04(25-46)$ \\
\hline Years of experience & $4.3 \pm 3.9(0-15)$ & $4.2 \pm 3.43(1-13)$ \\
\hline \multicolumn{3}{|l|}{ Education, $n(\%)$} \\
\hline $\mathrm{PhD} / \mathrm{MD}$ & $3(7 \%)$ & $2(13 \%)$ \\
\hline Masters & $24(56 \%)$ & $9(56 \%)$ \\
\hline Some graduate & $2(5 \%)$ & $1(6 \%)$ \\
\hline Bachelors & $13(30 \%)$ & $4(25 \%)$ \\
\hline Missing & $1(2 \%)$ & $0 \%$ \\
\hline \multicolumn{3}{|l|}{ Employer, $n$ (\%) } \\
\hline Ministry of Health & $1(2 \%)$ & $0 \%$ \\
\hline RASD Rwanda & $1(2 \%)$ & $0 \%$ \\
\hline Rwanda Biomedical Center & $3(7 \%)$ & $1(6 \%)$ \\
\hline University of Rwanda & $23(53 \%)$ & $8(50 \%)$ \\
\hline Kigali University Hospital & $3(7 \%)$ & $1(6 \%)$ \\
\hline Butare University Hospital & $2(5 \%)$ & $1(6 \%)$ \\
\hline District Hospital & $4(9 \%)$ & $1(6 \%)$ \\
\hline Other (e.g., NGO, hospital) & $5(12 \%)$ & $4(25 \%)$ \\
\hline Missing data & $1(2 \%)$ & $0 \%$ \\
\hline \multicolumn{3}{|l|}{ Position, $n$ (\%) } \\
\hline Assistant lecturer & $13(30 \%)$ & $6(38 \%)$ \\
\hline Other professional & $8(19 \%)$ & $4(25 \%)$ \\
\hline Tutorial assistant & $6(14 \%)$ & $2(13 \%)$ \\
\hline Physician & $5(12 \%)$ & $2(13 \%)$ \\
\hline Administrator & $4(9 \%)$ & $1(6 \%)$ \\
\hline Medical resident & $4(9 \%)$ & $0 \%$ \\
\hline Lecture & $2(5 \%)$ & $1(6 \%)$ \\
\hline Missing data & $1(2 \%)$ & $0 \%$ \\
\hline
\end{tabular}

background, and rationale" subscale improved by 1.23 points (pre-test $3.01 \pm 1.12$ to post-test $4.24 \pm 0.47$ ). The "theory and approaches" subscale improved by 1.15 points (pre-test $2.87 \pm 1.11$ to post-test $4.02 \pm 0.74$ ). The "design and analysis subscale" scores improved by 1.18 points (pre-test $2.69 \pm 1.10$ to post-test $3.87 \pm 0.78$ ). The final subscale, "practice-based considerations", improved by 1.33 points (pre-test $2.72 \pm 1.07$ to post-test $4.05 \pm$ $0.84)$.

The second sensitivity test results included the analytic sample, the outlier, and the other respondents who 
Table 2 D\&l competencies, pre- to post-test change in average scores (scale: $1=$ not at all; $5=$ extremely, $n=16$ )

\begin{tabular}{llll}
\hline & Pre-test & Post-test & $95 \% \mathrm{Cl}$ mean difference \\
\hline Definitions, background, and rationale & $3.11 \pm 1.05$ & $4.22 \pm 0.47$ & $.60-1.60$ \\
Theory and approaches & $2.99 \pm 1.04$ & $3.99 \pm 0.74$ & $.52-1.48$ \\
Design and analysis & $2.79 \pm 1.05$ & $3.84 \pm 0.79$ & $.56-1.54$ \\
Practice-based considerations & $2.83 \pm 1.01$ & $4.01 \pm 0.84$ & $.69-1.66$ \\
Full scale & $2.91 \pm 1.00$ & $4.00 \pm 0.70$ & $.64-1.53$ \\
\hline
\end{tabular}

completed the pre-/post-survey but only had partial responses on the D\&I competency scale. Their partial responses allowed us to create an average score. The results of the second sensitivity test are as follows $(n=$ 29 for all). The D\&I competency scores improved from pre- to post-test: the average full-scale score improved by 1.37 points (pre-test $2.63 \pm 1.10$ to post-test $4.00 \pm$ $0.71, t(28)=6.8577)$. The "definitions, background, and rationale" subscale improved by 1.28 points (pre-test $2.98 \pm 1.13$ to post-test $4.26 \pm 0.49$ ). The "theory and approaches" subscale improved by 1.37 points (pre-test $2.60 \pm 1.19$ to post-test $3.97 \pm 0.74$ ). The "design and analysis subscale" scores improved by 1.36 points (pretest $2.51 \pm 1.13$ to post-test $3.87 \pm 0.83$ ). The final subscale, "practice-based considerations", improved by 1.44 points (pre-test $2.60 \pm 1.12$ to post-test $4.04 \pm 0.82$ ). Across all three analyses, the conclusion remains unchanged: D\&I competency scores showed strong evidence of improvement for all pre- to post-test comparisons.

\section{Factors influencing trainee experience with the MOOC}

MOOC participants were solicited feedback regarding barriers to training, addressing MOOC course and internet connectivity and/or other issues. Trainees reported numerous barriers to the MOOC course. Many trainees reported that this course represented their first experience with internet-based training and raised concerns with apprehension and unclear expectations. All trainees stated that they have a full-time job with demanding schedules and raised concerns regarding the time commitment for course completion. Many completed the course during their personal time (i.e., evenings or weekends), which posed challenges related to conflicting priorities (i.e., family time vs. work). The MOOC's tight deadlines (i.e., completion of assignments) often posed challenges. Finally, many shared that completion of the final report was a big challenge for several reasons, the most commonly cited being that their expertise in implementation science was limited. Barriers regarding internet connectivity were raised by many trainees: highvariability of internet availability and inability to connect on a regular basis affected timely completion of assignments.

\section{Discussion}

Hypertension care is a pressing health problem in Rwanda. While there are treatment guidelines to strengthen care, selecting, adapting, and implementing these guidelines in low-middle-income countries is challenging [13]. One of the barriers in improving the quality of care for hypertension treatment is the limited capacity and infrastructure for T4 translational research. To address this issue, our research team has been training Rwandan stakeholders in D\&I to strengthen research infrastructure and human capacity [7]. Our ultimate goal is to co-create robust D\&I strategies to narrow the HTN care gap in Rwanda. This study examined whether the Special Programme for Research and Training in Tropical Diseases' MOOC could be used to provide D\&I training in Rwanda.

Our results show that $38 \%$ of those who officially enrolled completed the program. Historically, MOOC completion rates have varied [14-18]. In general, completion rates have been low [14-16], with some estimates as low as $6.5 \%$ [17]. The trainee completion rates were much higher than many [14-17] and are comparable to the higher completion rates (e.g. 53\%) reported by others [18]. Notwithstanding trainees expressing interest in and the utility of the training, they noted multiple barriers to complete the training's requirements. These barriers included challenges with the internet and the tight deadlines of the course. Being able to complete assignments and technology issues are barriers others have noted in regards to MOOC completion [19, 20].

The relatively high MOOC completion rate in the study's sample was most likely influenced by additional supports offered by the research team. For example, meetings were held with the trainees so they could meet the research team and previous MOOC trainees. During this meeting, trainees received an overview of the course, its form, modules, key dates, etc. Trainees also participated in Q\&A sessions to receive support for any challenges that had been raised. The research team also provided reminders and additional training sessions to manage technology-based questions. Other studies have found that similar strategies are important to support MOOC engagement [21]. It is unclear what the attrition rate with regards to our partners would have been without these additional supports. 
The results also indicate that the D\&I competency scale developed for a US-based training in D\&I with a focus on cancer $[10,12]$ has potential utility to evaluate other D\&I training programs. These D\&I competencies are described as self-efficacy skills and the present study's results are similar to the outcomes of other D\&I trainings showing an increase between pre- to post-test [12]. The skill that had the largest change was the "definitions, background, and rationale" subscale and the skills with the least change were the "theory and approaches" and "design and analysis" subscales, which corroborates with findings from other trainings [12]. A caveat to the present evaluation is that there were only two data points. The trainees will be invited to a second in-person training in the summer of 2019. Furthermore, the Special Programme for Research and Training in Tropical Diseases is developing D\&I research competencies for LMICs. Previous data suggest that, if mentored in D\&I skills, trainees show continued improvement in skills level over time [22]. It is our hope that we can continue fostering their learning and progress in advancing their D\&I research skills.

\section{Limitations}

The major limitations of this study are twofold: First, there was a high attrition rate in the MOOC training course (92 enrolled, 35 completed the course). This is attributed in great part to the barriers to training identified by the post-course survey, including apprehension and unclear expectations of the course, competing demands due to work and personal/family time, a significant time commitment and tight deadlines for course completion, and limited/inconsistent access to internet. We are working with our team to address these barriers for our next MOOC cohort (see Table 3). Second, there was a high attrition rate in survey follow-up. Of the MOOC participants, 74 responded to the pre-survey and 43 participants also responded to the post-survey (58\% attrition from pre to post). Of those participants who returned both the pre- and post-survey $(n=43)$, only 17 participants completed all the D\&I competency

Table 3 Summary of lessons learned about feasibility

Definition: Feasibility was defined as completion of MOOC assignments Main findings: $38 \%$ (37/92) of participants completed all requirements to receive the training certificate (Fig. 1). Largest attrition occurred at two points: (a) between enrollment and first quiz and (b) between quiz 4 and the final research proposal

Lessons learned and action items for future training:

1. Improve communication regarding course expectations

2. Increase time to submit assignments

3. Facilitate peer support by substituting single individual project for pair/group projects

4. Facilitate reliable access to internet

5. Provide video and transcript downloads to facilitate stakeholders offline use of training materials questions. One of those individuals was dropped from the analysis because they were an outlier, yielding an analysis sample with only $37 \%$ of the 43 surveys. Analysis showed that the group with missing D\&I competency data did not differ demographically from those with complete D\&I competency data. Two sensitivity tests were conducted to assess the durability of the findings. Both tests yielded the same conclusion that MOOC participants' D\&I competence improved. Of note, of the 35 MOOC participants who completed the training, $86 \%$ had complete pre/post D\&I competency scales. It is not possible to predict how our findings may have differed if all MOOC participants would have completed the preand post-survey.

Third, there was no comparator group and as such the improvement in D\&I competency scores could be attributed to factors other than the course itself. Fourth, some members of the research team knew the trainees, which could result in a "Hawthorne-effect" [23], where participants may falsely over-inflate their knowledge about D\&I contents after the training. Inflation of self-report assessments can be addressed with objective measures, such as scholarly outcomes (grants and publications) that examine D\&I competencies [24]. As a next step, Rwandan trainees are actively participating in our ongoing research projects and/or writing grant proposals applying D\&I concepts they learned. We are capturing grants submitted and awarded, as well as other scholarly outcomes (e.g., papers, conference presentations) in collaboration with our stakeholders. Finally, the completion rates were influenced by the additional supports offered by the study team. It is unclear what the completion rates would have been without those supports.

\section{Future directions}

Notwithstanding the challenges that trainees faced, the small sample size, and the issues inherent to online training, it seems that partnering with existing infrastructure such as the Special Programme for Research and Training in Tropical Diseases MOOC is a potentially scalable, free, and high-quality strategy to train LMIC partners in D\&I. Additional qualitative assessment will help identify strategies to support stakeholders in the next wave of training.

Using existing metrics, such as the D\&I competencies, will allow for generalizability and further evaluation on how to design training in D\&I. For example, the partnership's next D\&I training will focus on the skills that saw the least amount of change such as D\&I theories and designs. Further work could be done to compare the effectiveness of different modalities (e.g., in vivo, online), dose, and frequency in D\&I training across different settings in low-income 
countries and further identify how to objectively measure efficacy of trainings with non-academic trainees.

\section{Conclusions}

This study described the 2019 massive open online course (MOOC) for D\&I developed by the Special Programme for Research and Training in Tropical Diseases. The results show that partnering with existing infrastructures to provide D\&I training for trainees in LMICs is feasible and multiple barriers need to be addressed to improve participant retention. The report shares several lessons learned to address these barriers. Additionally, the report shows that the MOOC increased self-reported D\&I competencies from trainees in Rwanda. The partnership hopes that these lessons learned can help other groups in replicating and improving D\&I training, particularly in LMICs.

\section{Acknowledgements}

We would like to thank all MOOC course trainees for their participation and constructive comments regarding the program. We would like to thank the WUNDIR group from Washington University in St. Louis for their critical revisions to the manuscript. We appreciate the guidance provided by Dermot Maher, TDR Program Coordinator, who provided oversight of the training activity. We would like to thank Dr. Edith Certain for her continuous assistance in the development and implementation of the TDR MOOC on D\&l research. We also like to thank the TDR Special Programme for Research and Training in Tropical Diseases co-sponsored by UNICEF, UNDP, the World Bank, and WHO for their financial support for the MOOC program. Finally, TDR also received support from national governments, international institutions, as well as designated funding for specific projects within current TDR priorities. A full list of TDR donors can be found at: https://www.who.int/tdr/ about/funding/en/.

\section{Authors' contributions}

Drs. Bauman, Mutabazi, Brown, Launois, Mutimura, and Davila-Roman designed and led the study. Drs. Hooley and Baumann performed data analysis and initial writing of the manuscript. Both authors contributed equally as first authors. Drs. Mutabazi, Karengera, Reeds, Cade, de las Fuentes, Proctor, Schechtman, Goss, Launois, Newsome, and Cox contributed to the study implementation and writing of the manuscript. All authors read and approved the final manuscript.

\section{Authors' information}

Dr. Hooley is also now affiliated with the School of Social Work at Brigham Young University.

\section{Funding}

This work was supported in part by NHLBI grants U24 HL136790 and D43 TW10335. AB is also funded by the grants 3 U01HL133994-03S1 and UL1TR00234.

\section{Availability of data and materials \\ Data are available upon request}

\section{Ethics approval and consent to participate}

This study was approved by the University of Rwanda Institutional Review Board and the Washington University in St. Louis Institutional Review Board (IRB ID\# 201807048). All trainees were consented for this study.

\section{Consent for publication}

Consent was obtained from all trainees before the evaluations. Participation in the study was voluntary and not connected to the course performance. No monetary compensation was awarded.

\section{Competing interests}

The authors declare no competing interests.

\section{Author details}

${ }^{1}$ Brown School of Social Work, WUSTL, St. Louis, MO, USA. ${ }^{2}$ Regional Alliance for Sustainable Development (RASD) Rwanda, Kigali, Rwanda. ${ }^{3}$ Cardiovascular Division, WUSTL, St. Louis, MO, USA. ${ }^{4}$ Division of Geriatrics and Nutritional Science, WUSTL, St. Louis, MO, USA. ${ }^{5}$ Program in Physical Therapy, WUSTL, St. Louis, MO, USA. ${ }^{6}$ Division of Biostatistics, WUSTL, St. Louis, MO, USA. ${ }^{7}$ Special Programme for Research and Training in Tropical Diseases, WHO, Geneva, Switzerland.

Received: 1 October 2019 Accepted: 22 April 2020

Published online: 15 May 2020

References

1. World Health Organization. Prevention of cardiovascular disease guidelines for assessment and management of cardiovascular risk. Geneva, Switzerland 2007.

2. World Health Organizations. A global brief on hypertension: Silent killer, global public health crisis. Geneva, Switzerland: World Health Organization; 2013.

3. GBD 2013 Mortality and Causes of Death Collaborators. Global, regional, and national age-sex specific all-cause and cause-specific mortality for 240 causes of death, 1990-2013: A systematic analysis for the Global Burden of Disease Study 2013. The Lancet. 2015 Jan 10;385(9963):117-71.

4. World Health Organization. TDR strategy 2018-2023: building the science of solutions. Geneva; 2017.

5. TDR the Special Programme for Research and Training in Tropical Diseases. TDR implementation research toolkit [Internet]. [cited 2019 May 24]. Available from: http://adphealth.org/irtoolkit/.

6. Brownson RC, Proctor EK, Luke DA, Baumann AA, Staub M, Brown MT, et al. Building capacity for dissemination and implementation research: one university's experience. Implement Sci. 2017 Dec;12:104.

7. Potter C, Brough R. Systemic capacity building: a hierarchy of needs. Health Policy Plan. 2004 Sep;19(5):336-45.

8. Baumann AA, Mutabazi V, Brown AL, Hooley C, Reeds D, Ingabire C, Proctor EK. Dissemination and Implementation Program in Hypertension in Rwanda: Report on Initial Training and Evaluation. Glob Heart. 2019;14(2);135-41.

9. Taylor L, Adkins S, Hoel AW, Hauser J, Suwanabol P, Wood G, et al. Using implementation science to adapt a training program to assist surgeons with high-stakes communication. J Surg Educ. 2019 Jan;76(1):165-73.

10. Padek M, Colditz G, Dobbins M, Koscielniak N, Proctor EK, Sales AE, et al. Developing educational competencies for dissemination and implementation research training programs: an exploratory analysis using card sorts. Implement Sci. 2015 Aug 12;10(1):114.

11. Padek M, Brownson R, Proctor E, Colditz G, Kreuter M, Dobbins M, et al. Developing dissemination and implementation competencies for training programs. Implement Sci. 2015 Aug 14;10(S1):A39.

12. Padek M, Mir N, Jacob RR, Chambers DA, Dobbins M, Emmons KM, et al. Training scholars in dissemination and implementation research for cancer prevention and control: a mentored approach. Implement Sci. 2018 Jan 22;13(1):18.

13. Owolabi M, Olowoyo P, Miranda JJ, Akinyemi R, Feng W, Yaria J, et al. Gaps in hypertension guidelines in low- and middle-income versus high-income countries: a systematic review. Hypertension. 2016;68(6):1328-37.

14. Greene JA, Oswald CA, Pomerantz J. Predictors of retention and achievement in a massive open online course. Am Educ Res J. 2015 Oct 1;52(5):925-55.

15. Liyanagunawardena T, Adams A, Williams S. MOOCs: A systematic study of the published literature 2008-2012. Int Rev Res Open Distrib Learn. 2013; 14(3):202-27.

16. Foley K, Alturkistani A, Carter A, Stenfors T, Blum E, Car J, et al. Massive open online courses (MOOC) evaluation methods: protocol for a systematic review. JMIR Res Protoc. 2019 Mar 7;8(3):e12087.

17. Jordan K. Initial trends in enrolment and completion of massive open online courses. Int Rev Res Open Distrib Learn. 2014 Jan;15:15(1).

18. Murugesan R, Nobes A, Wild J. A MOOC approach for training researchers in developing countries. Open Prax. 2017 Mar 31;9(1):45-57.

19. Abidi SH, Pasha A, Ali S. Participant experience of the first massive open online course (MOOC) from Pakistan. Curr Issues Emerg ELearning. 2016;3(1):11.

20. Marcial DE, Caballero RDB, Rendal JB, Patrimonio GA. "I am offline": measuring barriers to open online learning in the Philippines. Inf Technol Learn Tools. 2015;45(1):28. 
21. Jung $Y$, Lee J. Learning engagement and persistence in massive open online courses (MOOCS). Comput Educ. 2018 Jul 1;122:9-22.

22. Luke DA, Baumann AA, Carothers BJ, Landsverk J, Proctor EK. Forging a link between mentoring and collaboration: a new training model for implementation science. Implement Sci. 2016 Oct 13;11(1):137.

23. Chiesa M, Hobbs S. Making sense of social research: how useful is the Hawthorne Effect? Eur J Soc Psychol. 2008;38(1):67-74.

24. Baumann AA, Carothers BJ, Landsverk J, Kryzer E, Aarons GA, Brownson RC, Glisson C, Mittman B, Proctor EK. Evaluation of the implementation research institute: Trainees' publications and grant productivity. Administration and Policy in Mental Health and Mental Health Services Research. 2020;47(2): 254-64.

\section{Publisher's Note}

Springer Nature remains neutral with regard to jurisdictional claims in published maps and institutional affiliations.

Ready to submit your research? Choose BMC and benefit from:

- fast, convenient online submission

- thorough peer review by experienced researchers in your field

- rapid publication on acceptance

- support for research data, including large and complex data types

- gold Open Access which fosters wider collaboration and increased citations

- maximum visibility for your research: over $100 \mathrm{M}$ website views per year

At $\mathrm{BMC}$, research is always in progress.

Learn more biomedcentral.com/submissions 